\title{
Probenecid as a sensitizer of bisphosphonate-mediated effects in breast cancer cells
}

Regina Ebert ${ }^{1}$, Jutta Meissner-Weigl', Sabine Zeck' , Jorma Määttä3 ${ }^{3}$, Seppo Auriola ${ }^{3}$, Sofia Coimbra de Sousa ${ }^{3}$, Birgit Mentrup ${ }^{1}$, Stephanie Graser ${ }^{1}$, Tilman D Rachner ${ }^{2}$, Lorenz C Hofbauer ${ }^{2}$ and Franz Jakob ${ }^{1 *}$

\begin{abstract}
Background: Anti-resorptive bisphosphonates (BP) are used for the treatment of osteoporosis and bone metastases. Clinical studies indicated a benefit in survival and tumor relapse in subpopulations of breast cancer patients receiving zoledronic acid, thus stimulating the debate about its anti-tumor activity. Amino-bisphosphonates in nM concentrations inhibit farnesyl pyrophosphate synthase leading to accumulation of isopentenyl pyrophosphate (IPP) and the ATP/ pyrophosphate adduct Apppl, which induces apoptosis in osteoclasts. For anti-tumor effects $\mu \mathrm{M}$ concentrations are needed and a sensitizer for bisphosphonate effects would be beneficial in clinical anti-tumor applications. We hypothesized that enhancing intracellular pyrophosphate accumulation via inhibition of probenecid-sensitive channels and transporters would sensitize tumor cells for bisphosphonates anti-tumor efficacy.
\end{abstract}

Methods: MDA-MB-231, T47D and MCF-7 breast cancer cells were treated with BP (zoledronic acid, risedronate, ibandronate, alendronate) and the pyrophosphate channel inhibitors probenecid and novobiocin. We determined cell viability and caspase 3/7 activity (apoptosis), accumulation of IPP and Apppl, expression of ANKH, PANX1, ABCC1, SLC22A11, and the zoledronic acid target gene and tumor-suppressor KLF2.

Results: Treatment of MDA-MB-231 with BP induced caspase 3/7 activity, with zoledronic acid being the most effective. In MCF-7 and T47D either BP markedly suppressed cell viability with only minor effects on apoptosis. Co-treatment with probenecid enhanced BP effects on cell viability, IPP/Apppl accumulation as measurable in MCF-7 and T47D cells, caspase 3/7 activity and target gene expression. Novobiocin co-treatment of MDA-MB-231 yielded identical results on viability and apoptosis compared to probenecid, rendering SLC22A family members as candidate modulators of BP effects, whereas no such evidence was found for ANKH, ABCC1 and PANX1.

Conclusions: In summary, we demonstrate effects of various bisphosphonates on caspase 3/7 activity, cell viability and expression of tumor suppressor genes in breast cancer cells. Blocking probenecid- and novobiocin-sensitive channels and transporters enhances BP anti-tumor effects and renders SLC22A family members good candidates as BP modulators. Further studies will have to unravel if treatment with such BP-sensitizers translates into preclinical and clinical efficacy.

Keywords: Bisphosphonates, Caspase 3/7 activity, Cell viability, Probenecid, Novobiocin, Breast cancer cells

\footnotetext{
* Correspondence: f-jakob.klh@uni-wuerzburg.de

'Orthopedic Center for Musculoskeletal Research, University of Würzburg,

Brettreichstrasse 11, 97074 Würzburg, Germany

Full list of author information is available at the end of the article
} 


\section{Background}

Bone metastases occur exceptionally often in cancers derived from the breast, the prostate and the kidney. The biological process of metastasis requires the capability of extravasation, migration and homing to the bone microenvironment. Tumor cells when metastasized to bone are able to activate osteoclasts by secreting osteoclast promoting factors [1]. The latter is the basis of the classical concept of osteolytic metastasis, while the local secretion and/ or activation of latent growth factors contribute to the development of osteoblastic metastases and autocrine tumor propagation [2].

Anti-resorptive bisphosphonates (BP) accumulate in bone as they show a high affinity to hydroxylapatite and are incorporated by osteoclasts via phagocytosis [3]. First generation BP like clodronate induce apoptosis by accumulating toxic ATP adducts whereas second generation amino-BP inhibit the mevalonate pathway enzyme farnesyl pyrophosphate synthase (FPPS) very specifically. As a consequence protein prenylation of small GTP binding proteins like Rab, Ras or lamins, which are important for cytoskeleton organization and cellular polarization, is inhibited and may initiate apoptosis [4]. Additionally it was reported for zoledronic acid (ZA) and to a lesser extend for ibandronate (IBN) and risedronate (RIS) as well as for alendronate (ALN) that treatment of cells led to the accumulation of isopentenyl pyrophosphate (IPP) and produced a new endogenous ATP analogue (triphosphoric acid 1-adenosin-5' -yl ester 3-(3-methylbut-3-enyl) ester (ApppI)), which also caused apoptosis in osteoclasts by inhibiting the mitochondrial ADP/ATP translocase [5].

BP have been developed for osteoporosis treatment where numerous clinical studies proved their efficacy in reducing the incidence of fragility fractures. When applied in higher cumulative doses than used for osteoporosis, BP effectively reduced the number of skeletal related events in patients with bone metastases [6,7], which has made them an important class of drugs in the treatment of osteolytic bone diseases [8]. Besides the effects on their classical targets, cells of the myelomonocytic/macrophage lineage and especially osteoclasts, BP have been shown to induce apoptosis in a variety of benign and malignant cells, although in some cases $\mu \mathrm{M}$ concentrations were required [3]. These in vitro effects in concert with clinical studies have stimulated discussions about a putative clinically relevant anti-tumor effect of BP. Almost twenty years ago it was shown that adjuvant treatment with BP reduces the incidence of bone metastases and the overall mortality in patients suffering from breast cancer. These results were confirmed in the ABCSG-12 trial, where ZA was used only twice a year for the adjuvant treatment of estrogen receptor positive breast cancer patients. Positive long term effects from patients of the first cohort were reported in a second analysis more than ten years after the first publication [9-11]. Moreover, a synergistic anticancer efficacy of ZA in combination with neoadjuvant chemotherapy was shown in breast cancer patients with respect to additional tumor shrinkage [12]. These effects were confirmed by the ZO-FAST study, where ZA was associated with improved disease-free survival in postmenopausal women [13]. However, the discussion is ongoing and presently a proven anti-tumor effect seems to be restricted to the postmenopausal high bone turnover subpopulation of women suffering from breast cancer [14].

The detailed characterization of the molecular effects of modern BP like ZA stimulated research about their effects on both osteoblastic differentiation and on antitumor effects, but a prominent question remained to be solved, if local $\mu \mathrm{M}$ concentrations of BP can be achieved in the clinical setting $[15,16]$. Such high concentrations are needed because the cellular uptake is relatively poor in cells other than macrophages and osteoclasts as described for e.g. free ZA in ovarian tumor cells [17]. However it was speculated that BP concentrations in the bone microenvironment and especially in the resorption lacuna can reach concentrations up to hundreds of $\mu \mathrm{M}$ [18]. The two most prominent in vitro effects of $\mathrm{BP}$, which may add to their putative anti-tumor effects, are the capability of inducing apoptosis in tumor cells and eliciting an immune response. Stimulation of breast cancer cells with bisphosphonates and inhibition of the mevalonate pathway as a consequence leads to the accumulation of IPP and ApppI. IPP acts as phosphoantigen for $\gamma \delta \mathrm{T}$ cells, which have the ability to attack the tumor cells [19]. The mechanism by which IPP is secreted or transported to the outer surface of a cell is still unknown [20,21]. Channels and transporters for pyrophposphates or ATP might be responsible for mediating these effects and promising candidates are pannexin (PANX) hemichannels (especially PANX1), the progressive ankylosis protein homolog ANKH as well as organic anion transporters of the solute carrier family 22 (organic anion transporter SLC22A6, SLC22A8 and SLC22A11) and multidrug resistance associated protein 1 (ABCC1). For PANX1, which is a part of the purinergic receptor P2RX7 complex, participation in ATP release was shown [22-24]. ANKH is a transmembrane protein and controls intra- and extracellular levels of pyrophosphate, which is important in bone mineralization [25]. Solute carrier family 22 members are responsible for the transport of organic anions mainly in the kidney and liver [26] whereas $A B C C 1$, a member of the human $A B C$ transporter family that is involved in multidrug resistance, mediates export of organic anions and drugs from the cytoplasm [27]. All channels and transporters are sensitive to the anion transport blocker probenecid (Prob), whereas carbenoxolone (CBX) has no effect on ANKH but is effective in inhibiting PANX1 mediated release. Ibrutinib was described to block $\mathrm{ABCC} 1$ transport while 
novobiocin inhibits SLC22A6, 8 and 11 [24,28-31]. Therefore these substances can be used to distinguish between ANKH, PANX1, ABCC1 and SLC22A mediated effects.

Sustained effects of bisphosphonates on osteogenic differentiation upon treatment with low concentrations and intermittent treatment with high concentrations of ZA and alendronate were previously demonstrated [32,33], while permanent exposure to high doses induced apoptosis in both tumor cells and osteogenic precursors [32,34,35]. In MCF-7 cells we identified ZA target genes as KLF2, KLF6 and Ki-67 and we assumed that IPP/ApppI accumulation might mediate this effect in cell populations that are largely insensitive to apoptosis induction [15]. It is of major importance to unravel the differential potency of various BP on tumor cell growth and apoptosis and to describe the downstream targets in non-osteoclastic cells.

Here we show that breast cancer cell lines permanently exposed to various BP (zoledronic acid, ibandronate, alendronate, risedronate) undergo apoptosis (MDA-MB-231, to a lesser extend T47D) or show reduced viability (MCF-7). The relative potency of various BP mirrors their antiosteolytic potency with ZA inducing the greatest increase in apoptosis. Interestingly, all other BP tested were almost equally potent in reducing MCF-7 viability. Co-incubation with the anion transporter and channel blocking agent probenecid and novobiocin revealed a synergistic effect,
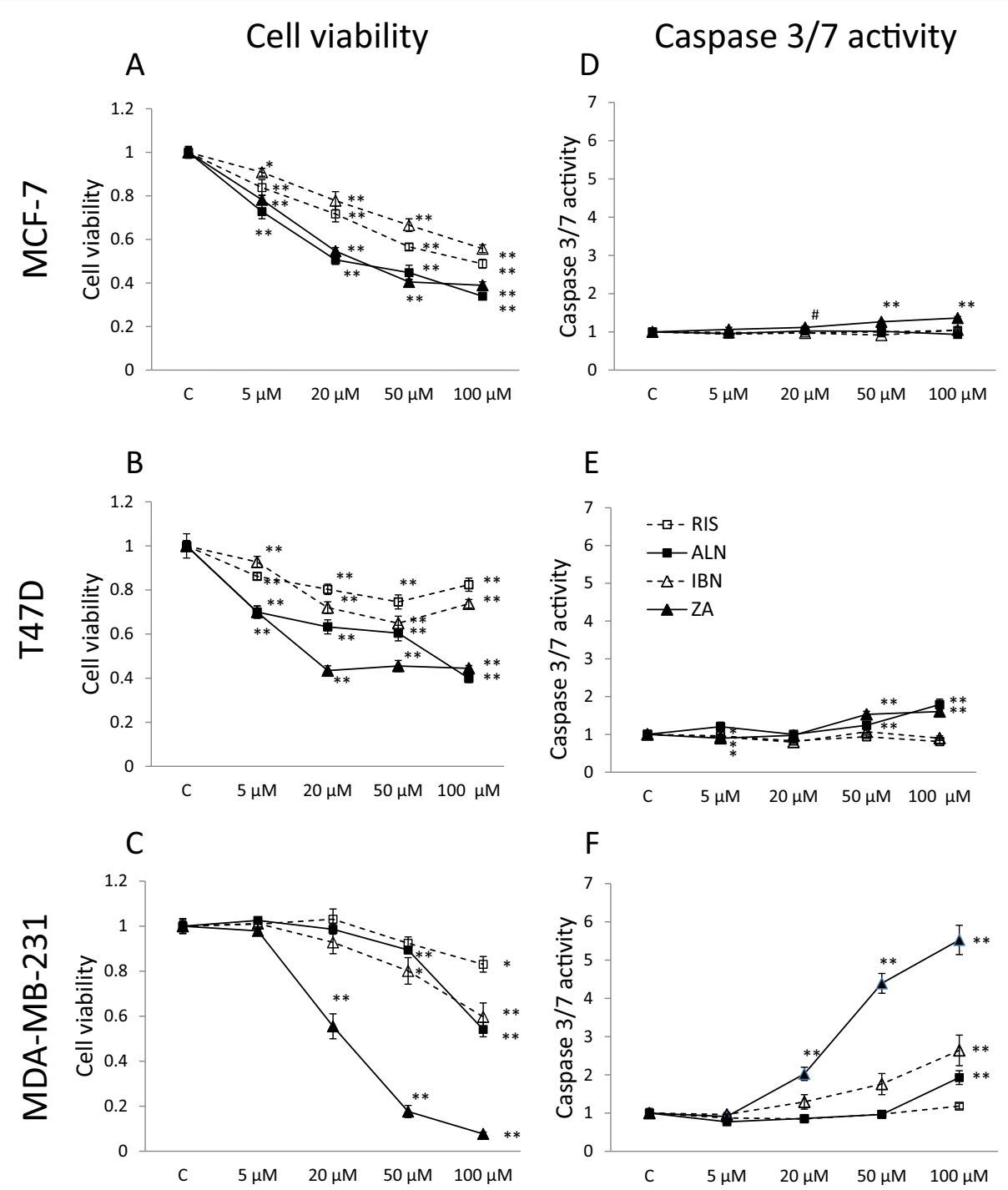

Figure 1 Cell viability and caspase 3/7 activity in breast cancer cells treated with various bisphosphonates. Cell viability (A-C) and caspase 3/7 activity (D-F) in MCF-7, T47D and MDA-MB-231 breast cancer cells treated with 5-100 $\mu$ M zoledronic acid (ZA, filled triangles), ibandronate (IBN, open triangles), alendronate (ALN, filled squares) and risedronate (RIS, open squares). All data are expressed as means of six different measure points of three independent experiments as percent of controls \pm SEM. Significances were calculated with the Mann-Whitney $U$ test $\left({ }^{* *} p<0.001,{ }^{*} p<0.01,{ }^{*} p<0.05\right)$. 
which shows that accumulated pyrophosphates might be secreted to the extracellular space and according to previously described sensitivity renders SLC22A family members as good candidates for the sensitizing effects. Bisphosphonates have relevant effects on tumor cell biology and an adjuvant therapy with BP in combination with a respective sensitizer might be useful in the treatment of breast cancer.

\section{Results}

Permanent incubation of breast cancer cell lines with different bisphosphonates modulates cell viability and caspase $3 / 7$ activity

MCF-7, T47D and MDA-MB-231 cells were subjected to various concentrations of ZA, IBN, ALN and RIS (5, 20, 50 and $100 \mu \mathrm{M}$ ) for $72 \mathrm{~h}$ (Figure 1 ). In MCF-7 cell viability was inhibited by all used bisphosphonates (Figure 1A). $100 \mu \mathrm{M}$ ZA and ALN suppressed the viability to 40\%, RIS and IBN to $50-60 \%$. In T47D cells ZA inhibited the viability to $40 \%$ starting from $20 \mu \mathrm{M}$ with no increasing effects when higher doses were used. ALN was less potent when applied at 20 and $50 \mu \mathrm{M}$ but showed the same inhibition at $100 \mu \mathrm{M}$. RIS and IBN reduced cell viability only to approx. 70 and $80 \%$ in a U-shaped manner when applied in doses of $50 \mu \mathrm{M}$ and higher (Figure 1B). ZA was most potent in inhibiting the viability of MDA-MB-231 cells (Figure $1 \mathrm{C}$, filled triangles). 20 and $50 \mu \mathrm{M}$ ZA reduced cell viability to 50 and $20 \%$, respectively. IBN (open triangles) and ALN (filled squares) were less potent, while RIS (open squares) had almost no effect.

In MCF-7 cells only ZA showed marginal effects on caspase $3 / 7$ induction (Figure 1D) while in T47D cells only ZA and ALN slightly enhanced caspase $3 / 7$ activity when applied in 50 and $100 \mu \mathrm{M}$ doses (Figure 1E). When analyzing caspase 3/7 activity of MDA-MB-231 cells (Figure 1F) treated with different bisphosphonates $100 \mu \mathrm{M}$ ZA induced a 5-fold enhancement (filled triangles), while IBN (open triangles) was able to increase caspase 3/7 activity 2-fold compared to ALN (filled squares, 1.5-fold) at the same concentration. RIS (open squares) had no effect on caspase 3/7 activity in MDA-MB-231 cells. No effect of ZA on cytotoxicity could be observed (data not shown).

Significances were calculated with the Mann-Whitney $U$ test by comparison of the untreated controls to the stimulated values (** $\left.\mathrm{p}<0.001,{ }^{*} \mathrm{p}<0.01,{ }^{*} \mathrm{p}<0.05\right)$.

\section{Bisphosphonate treatment induces IPP/Apppl production in breast cancer cells}

The accumulation of IPP and ApppI was analyzed in MCF-7, T47D and MDA-MB-231 breast cancer cells after treatment with the bisphosphonates ZA, RIS, IBN and ALN, respectively. By comparing the three different cell lines high concentrations of IPP were detected in T47D and MCF-7 cells while ApppI concentrations were high in T47D and moderate in MCF-7 cells. No reproducible amounts of IPP and ApppI could be measured in MDA-MB-231 cells as it was reported before [19] (data not shown). In T47D cells ZA induced high amounts of IPP $(6,820 \mathrm{pmol} / \mathrm{mg}$ protein) while RIS treatment resulted in the accumulation of moderate levels $(5,500 \mathrm{pmol} / \mathrm{mg}$ protein) (Figure 2A, right bars) in contrast to ALN and IBN, which induced lower IPP accumulation (3,336 pmol/ $\mathrm{mg}$ protein and 2,838 $\mathrm{pmol} / \mathrm{mg}$ protein, respectively) although with high variability when IBN was applied. Determination of ApppI revealed similar concentrations after treatment with ZA and RIS (1,210 and 1,165 pmol/mg protein) (Figure 2B, right bars). Determination of ApppI concentrations after ALN treatment showed a moderate induction of $742 \mathrm{pmol} / \mathrm{mg}$ protein while IBN treated cells accumulated only $294 \mathrm{pmol}$ ApppI/mg protein. In MCF-7 cells ZA and RIS stimulation resulted in the accumulation of 4,674 and 4,520 $\mathrm{pmol} \mathrm{IPP} / \mathrm{mg}$ protein while values for ALN treated cells were moderate $(3,250 \mathrm{pmol} / \mathrm{mg}$ protein) with IPP only detectable in two out of three ALN treated samples. IPP concentrations for IBN treated cells were lowest (940 $\mathrm{pmol} / \mathrm{mg}$ protein) (Figure 2A, left bars). ApppI values in MCF-7 cells were much lower compared to the

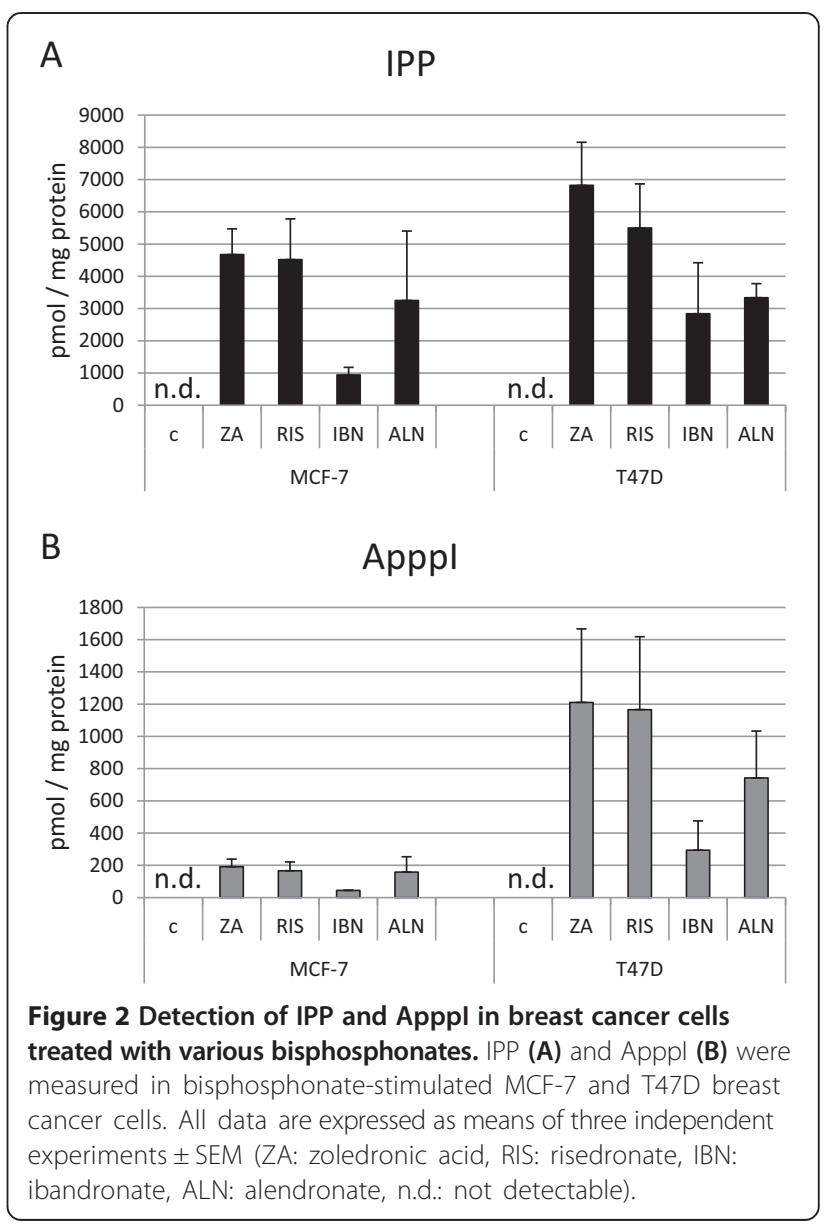


values observed in T47D cells. In ZA, RIS and ALN stimulated cells ApppI values were between 191 and 156 pmol/ mg protein, with ApppI only detectable in two out of three ALN treated samples. ApppI was only measureable in one out of three samples in IBN treated cells (Figure 2B, left bars). In MDA-MB-231 cells IPP and ApppI were detectable in only one out of three samples (data not shown).

\section{Probenecid co-treatment enhances bisphosphonate effects on cell viability and caspase $3 / 7$ activity} MCF-7, T47D and MDA-MB-231 breast cancer cells were stimulated with 20, 50 and $100 \mu \mathrm{M}$ ZA, RIS, IBN, or ALN, respectively (Figure 3 , black lines) and cotreated with $0.25 \mathrm{mM}$ probenecid (Prob, Figure 3, dotted lines) for $72 \mathrm{~h}$. Determination of cell viability in MCF-7 cells (Figure 3A-D) revealed a synergistic effect of probenecid on $\mathrm{BP}$ effects compared to $\mathrm{BP}$ alone with almost parallel curves in terms of RIS and IBN. In ZA and ALN treated cells, probenecid showed additive effects when submaximal BP doses of $20 \mu \mathrm{M}$ were applied. With a higher BP dosing the curves almost converged. In T47D cells (Figure 3E-H) Prob and RIS co-stimulation had no additive effect on the inhibition of cell viability compared to cells treated with RIS alone in contrast to ZA or IBN stimulated cells, where Prob co-treatments increased the inhibitory effect of the respective BP. The effects of ZA and IBN obtained in T47D and MCF-7 cells were comparable in contrast to ALN stimulated T47D cells where the pattern of cell viability was different to all other BP. Prob co-stimulation had maximal effects at an ALN range between 20 and $50 \mu \mathrm{M}$ and depicted much less impact on cell viability at higher $\mathrm{BP}$ concentrations. In MDA-MB-231 cells (Figure 3I-L) ZA/Prob and ALN/ Prob co-treatment experiments revealed comparable results as well as in RIS/Prob and IBN/Prob treated specimens, respectively. The graphs of RIS and IBN single treated cells diverged from the RIS/Prob and IBN/Prob co-stimulations with a maximum at $100 \mu \mathrm{M}$ BP, whereas the graphs of ZA and ALN single treated cells diverged from the ZA/Prob and ALN/Prob co-treatments maximally at a concentration of $20 \mu \mathrm{M}$ BP and converged at higher doses at $100 \mu \mathrm{M}$.

Determination of caspase $3 / 7$ activity in $\mathrm{BP} /$ Prob costimulated MCF-7 cells (Figure 3M-P) revealed an activity induction at concentrations of 20 and $50 \mu \mathrm{M}$ ZA and RIS after Prob stimulation, whereas the combination of $20 \mu \mathrm{M}$ IBN and Prob inhibited caspase $3 / 7$ activity in contrast to doses of 50 and $100 \mu \mathrm{M}$ IBN where Prob had a slight but measurable additive effect. No additive effect of Prob and ALN could be observed. In T47D cells (Figure 3Q-T) no caspase $3 / 7$ activity was induced by RIS and IBN, as we have already shown in Figure 1, and IBN/Prob or RIS/Prob co-stimulations did not show any activity induction, RIS/Prob even reduced the measured caspase 3/7 activity. An additive effect of ZA/Prob was seen compared to ZA single stimulated samples at 50 and $100 \mu \mathrm{M}$ ZA whereas the combination of ALN and Prob showed massive effects on caspase $3 / 7$ activity induction at all ALN concentrations compared to ALN stimulations alone. When we determined the activity of caspase 3/7 in MDA-MB-231 (Figure 3U-X) after stimulating cells with $\mathrm{BP}$ alone or in combination with Prob we observed an additive effect of Prob/BP in combination compared to $\mathrm{BP}$ alone in ZA and ALN treated cells at 20 and $50 \mu \mathrm{M}$ $\mathrm{BP}$, although at higher doses of $100 \mu \mathrm{M}$ caspase 3/7 activity was diminished in the $\mathrm{BP} /$ Prob samples compared to the BP stimulated specimens. IBN/Prob co-treatment increased caspase $3 / 7$ activity compared to IBN single stimulated cells at all concentrations whereas in RIS treated cells RIS/Prob co-treatment had the opposite effect and caspase $3 / 7$ activity was reduced.

Significances were calculated with the Mann-Whitney $U$ test by comparison of the BP stimulated samples to the BP/Prob co-treated values $\left({ }^{* *} \mathrm{p}<0.005,{ }^{*} \mathrm{p}<0.05\right)$.

\section{Probenecid enhances BP-induced IPP/Apppl accumulation} IPP and ApppI accumulation was measured in breast cancer cells after co-stimulation with bisphosphonates and probenecid. In MCF-7 cells (Figure 4A) Prob co-treatment significantly increased the BP induced accumulation of IPP (black bars) in ZA, RIS and IBN treated samples. The highest effect was obtained after IBN/Prob co-stimulation, where a 3.2-fold increase of IPP values was obtained compared to IBN treatment alone. The determination of ApppI revealed only a significant additive effect of Prob on ZA treated samples (grey bars). In only two out of three ALN/ Prob co-stimulated samples IPP and ApppI could be detected while only one out of three IBN/Prob samples depicted ApppI accumulation. In T47D cells (Figure 4B) Prob co-treatment increased the BP induced accumulation of IPP (black bars) and ApppI (grey bars) with significant values in RIS and ALN specimens in terms of IPP and significant values in ZA, RIS and ALN treated samples in terms of ApppI accumulation. The combination Prob/ ALN was most effective with a 3-fold increase in IPP and a 3.5-fold increase in ApppI accumulation compared to ALN treated samples alone. In MDA-MB-231 cells IPP could be detected after ZA/Prob and ALN/Prob co-treatment. All other samples were negative for IPP and ApppI, respectively (data not shown). Significances were calculated from the means of three independent experiments with the Mann-Whitney $U$ test ${ }^{* * * *} \mathrm{p}<0.005$, $\left.{ }^{*} \mathrm{p}<0.05\right)$.

\section{Probenecid co-treatment enhances bisphosphonate-induced} expression of the target gene KLF2

We have previously identified KLF2 as a target gene of ZA in MCF-7 cells [15] and postulated its specific upregulation 


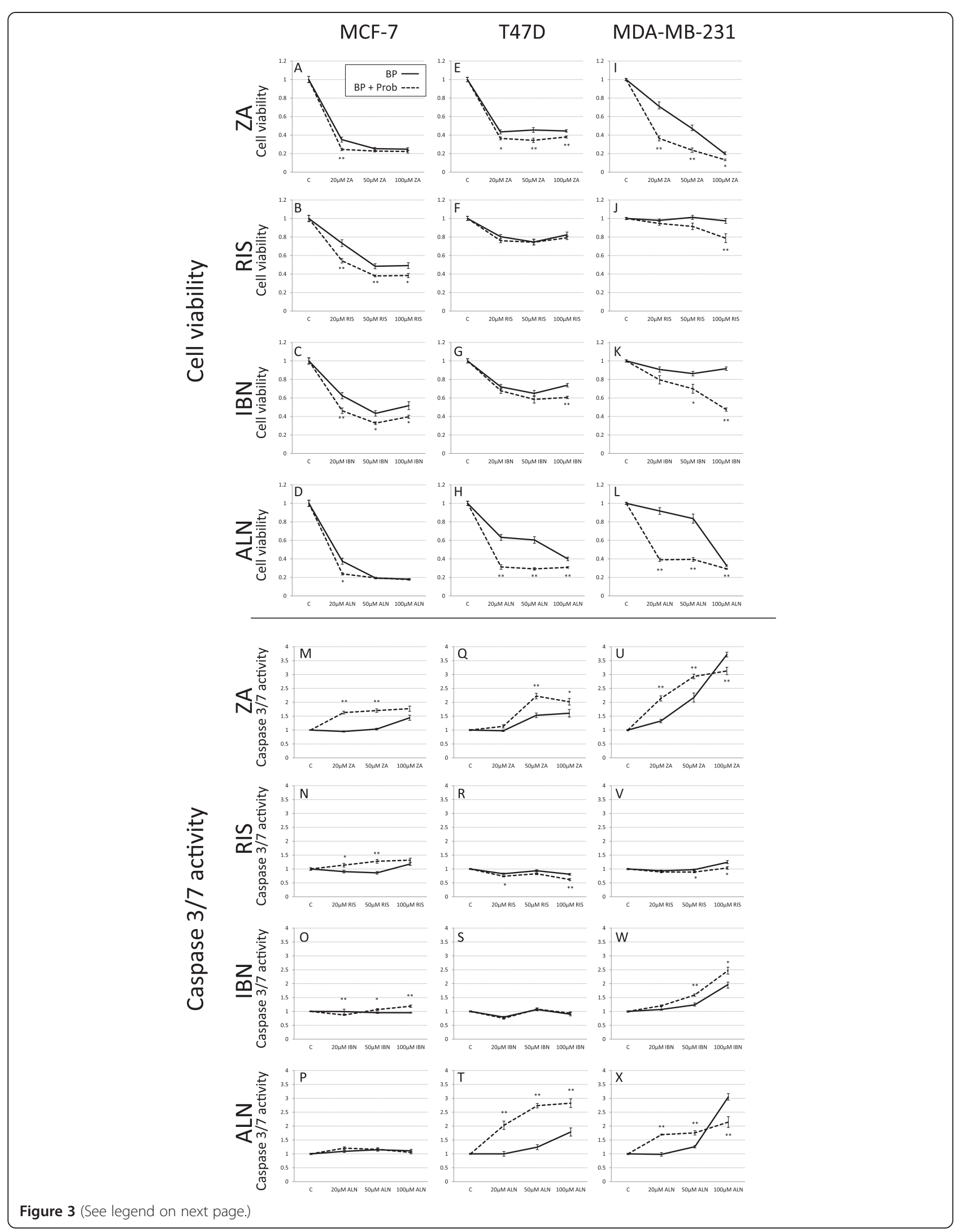


(See figure on previous page.)

Figure 3 Cell viability and caspase $3 / 7$ activity in breast cancer cells co-treated with probenecid and bisphosphonates. Cell viability (A-L) and caspase 3/7 activity (M-X) was determined in MCF-7, T47D and MDA-MB-231 breast cancer cells after treatment with ZA (zoledronic acid), RIS (risedronate), IBN (ibandronate), ALN (alendronate) alone and in combination with probenecid. All data are expressed as means of six different measure points of three independent experiments as percent of controls \pm SEM. Significances were calculated with the Mann Whitney $U$ test $\left({ }^{* *} p<0.005,{ }^{*} p<0.05\right)$. BP: bisphosphonate, black line; Prob: probenecid, dotted line probenecid co-treatment.

by intracellular BP effects, e.g. IPP/ApppI accumulation and inhibition of protein prenylation. We analyzed if other $\mathrm{BP}$ are also able to modulate KLF2 expression in breast cancer cells and if probenecid can enhance the observed effects. In MCF-7 cells ZA induced a 13-fold increase in KLF2 expression, which was further enhanced by Prob cotreatment (32.4-fold expression) compared to untreated controls (Table 1). Additive effects of Prob were also observed when using ALN. The bisphosphonate alone induced KLF2 expression by the factor 5.8 with a further stimulatory effect of Prob co-treatment to a 36.1-fold induction. IBN alone had no impact on KLF2 expression but

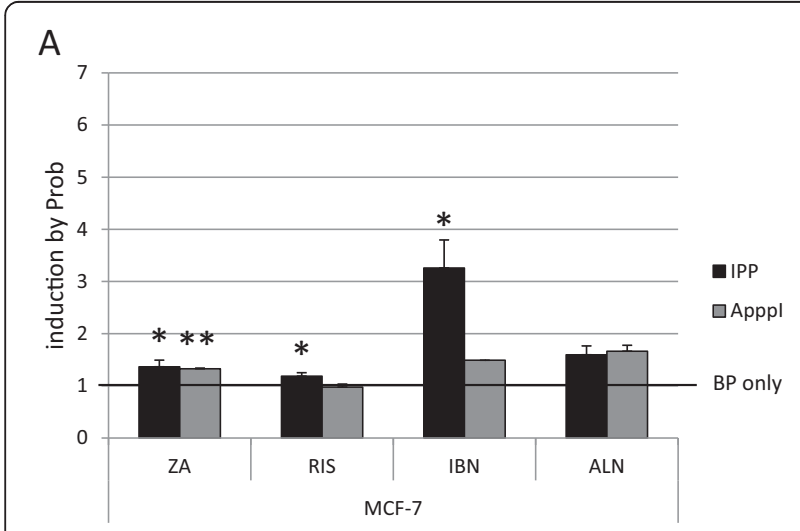

B

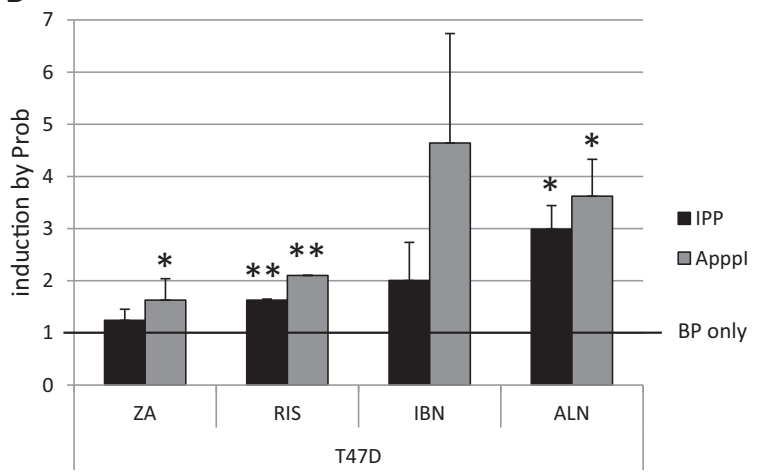

Figure $\mathbf{4}$ Induction of IPP and Apppl in bisphosphonate-stimulated breast cancer cells by probenecid. MCF-7 (A) and T47D (B) cells were treated with ZA (zoledronic acid), RIS (risedronate), IBN (ibandronate), ALN (alendronate) alone and in combination with probenecid (Prob). All data are expressed as means of three independent experiments \pm SEM. The induction of IPP (black bars) and Apppl (grey bars) in BP stimulated cells by Prob is shown. Significances were calculated with the Mann-Whitney $U$ test $\left({ }^{* *} p<0.005,{ }^{*} p<0.05\right)$. with Prob co-stimulation the expression of KLF2 increased 6.1-fold in contrast to RIS, where no co-stimulatory effect of Prob on the absent RIS effect could be observed.

In MDA-MB-231 cells ZA and IBN had no significant impact on KLF2 expression but Prob was able to increase KLF2 expression 5.1-fold in ZA and 4.8-fold in IBN costimulatory experiments. RIS alone increased KLF2 expression by the factor 3.5 but Prob co-treatment abandoned the effect to a non-significant expression. No effect was seen when ALN was used, independent of Prob cotreatment.

In T47D cells no additive effect of Prob was detectable. ZA increased KLF2 expression 3.0 fold but Prob had no additive effect (2.6-fold expression) just as in terms of IBN, where both IBN and IBN/Prob treated samples showed an upregulation of KLF2 by the factor 2.2. RIS alone increased KLF2 expression by the factor 2.1 but no significant enhancement was detectable in RIS/Prob treated cells. ALN alone or the combination ALN/Prob did not influence the expression of KLF2.

\section{Breast cancer cells express probenecid sensitive channels} and transporters

The expression of the pyrophosphate channel ankylosis protein homolog (ANKH), the hemichannel protein pannexin 1 (PANX1), multidrug resistance associated protein 1 (ABCC1) and solute carrier family 22 (organic anion

Table 1 Effects of co-treatment of breast cancer cell lines with probenecid and bisphosphonates on the expression of KLF2

\begin{tabular}{|c|c|c|c|}
\hline KLF2 expression & MCF-7 & T47D & MDA-MB-231 \\
\hline $\mathrm{ZA} 20 \mu \mathrm{M}$ & $13.0^{* *}(2.3-60.8)$ & $3.0^{*}(1.2-7.6)$ & $3.1(0.6-16.0)$ \\
\hline$Z A+$ Prob & $32.4^{* *}(5.8-198.5)$ & $2.6^{*}(1.0-6.7)$ & $5.1^{*}(0.7-25.6)$ \\
\hline RIS $50 \mu \mathrm{M}$ & $1.6(0.3-10.1)$ & $2.1^{*}(1.0-3.7)$ & $3.5^{*}(0.6-18.8)$ \\
\hline RIS + Prob & $4.2(0.7-35.9)$ & $1.7(0.7-4.7)$ & $3.4(0.5-19.2)$ \\
\hline IBN $50 \mu \mathrm{M}$ & $2.4(0.5-15.2)$ & $2.2^{*}(0.9-4.9)$ & $2.4(0.3-17.3)$ \\
\hline $\mathrm{IBN}+$ Prob & $6.1 *(0.8-31.7)$ & $2.2^{*}(0.9-5.9)$ & $4.8^{* *}(0.7-28.4)$ \\
\hline ALN $50 \mu \mathrm{M}$ & $5.8^{*}(1.2-33.4)$ & $2.0(0.8-5.5)$ & $1.4(0.2-11.4)$ \\
\hline ALN + Prob & $36.1^{* *}(9.7-141.4)$ & $1.8(0.8-5.6)$ & $3.2(0.4-31.1)$ \\
\hline Prob & $1.0(0.3-5.0)$ & $1.0(0.8-1.3)$ & $1.3(0.1-9.4)$ \\
\hline
\end{tabular}

The expression ratios of KLF2, in MCF-7, T47D and MDA-MB-231 breast cancer cells after treatment with ZA (zoledronic acid), RIS (risedronate), IBN (ibandronate), ALN (alendronate) alone and in combination with probenecid (Prob) compared to untreated controls and normalized to 36B4 (acidic ribosomal phosphoprotein P0) are shown. ${ }^{* *} \mathrm{p}<0.001,{ }^{*} \mathrm{p}<0.01$ calculated with REST [38]). 
transporter) member 6, 8 and 11 (SLC22A6, SLC22A8, SLC22A11) were analyzed in breast cancer cells. PANX1 transcripts could be detected in high amounts in all tested cell lines. ANKH was highly expressed in MCF-7 and MDA-MB-231 cells in contrast to T47D cells where only a faint PCR band was visible. ABCC1 was highly expressed in MCF-7 cells and lower in T47D and MDA-MB-231 cells. SLC22A11 was expressed in T47D and MDA-MB231 but not in MCF-7 cells (Figure 5). SLC22A6 and SLC22A8 mRNAs were not detectable in all analyzed breast cancer cell lines. QPCR quantification of ANKH expression revealed a 0.18 -fold $(\mathrm{p}<0.05)$ lower expression in MCF-7 cells and a 0.07 -fold $(\mathrm{p}<0.001)$ lower expression in T47D cells compared to MDA-MB-231 cells whereas PANX1 and ABCC1 expression varied between the cell lines but without any significance. Values were normalized to 36B4 expression (MDA-MB-231 vs. MCF-7) and GAPDH (MDA-MB-231 vs. T47D). Immunocytochemical staining of ANKH and PANX protein confirmed these results with MCF-7 and MDA-MB-231 cells expressing high levels, and T47D expressing low levels of ANKH while PANX1 was equally expressed among the cell lines (Additional file 1: Figure S1).

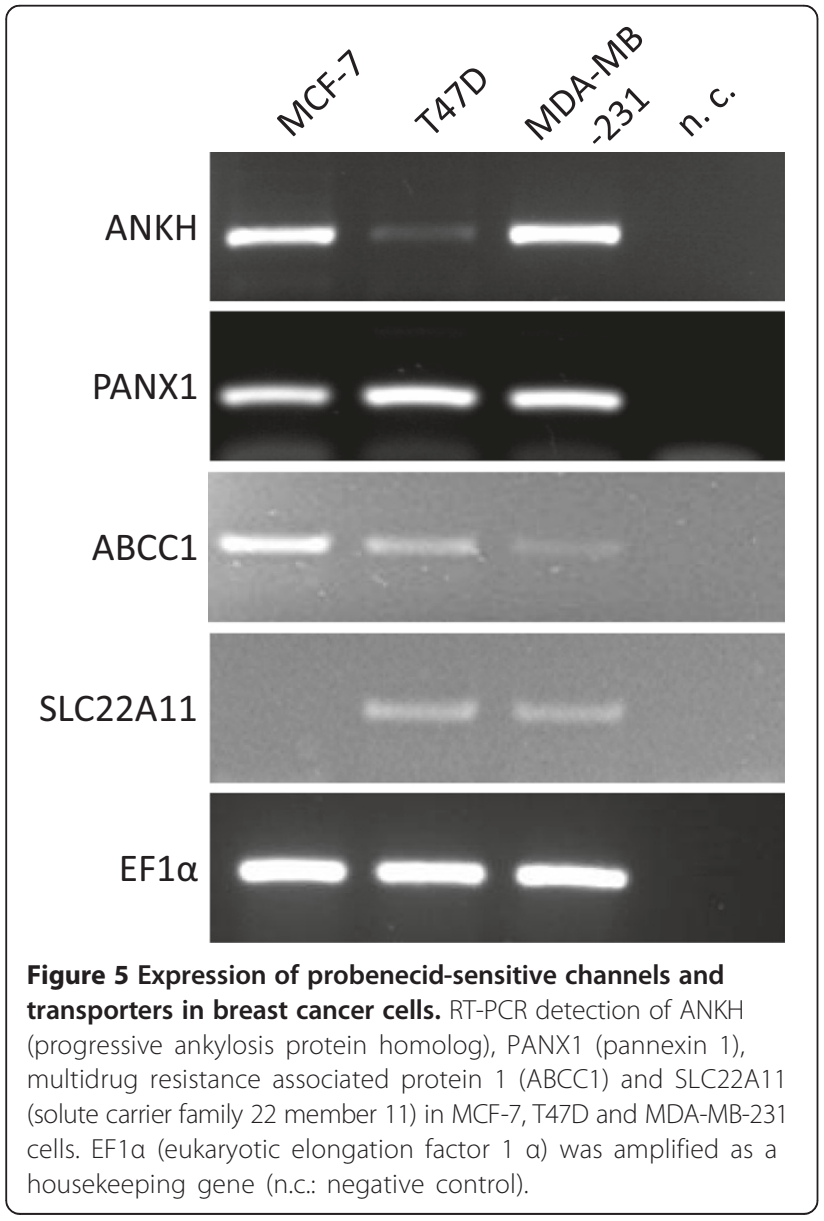

ANKH overexpression does not alter probenecid response of BP effects on cell viability

Expression of ANKH in stably transfected T47D cells (T47D-pCMV-ANKH) was confirmed by RT-PCR on mRNA (Additional file 2: Figure S2A) and by immunocytochemistry on protein level (Additional file 2: Figure S2B). When ANKH overexpressing T47D cells and T47D control cells carrying the empty pCMV vector were stimulated with 20 and $50 \mu \mathrm{M}$ ZA (Additional file 2: Figure S2C, black line) and co-stimulated with $0.25 \mathrm{mM}$ Prob (Additional file 2: Figure S2C, dotted line) no difference between the two cell lines was observed in terms of cell viability and caspase $3 / 7$ activity.

\section{Novobiocin but not carbenoxolone or ibrutinib} co-treatment modulates bisphosphonate effects on cell viability and caspase $3 / 7$ activity in MDA-MB-231 breast cancer cells

To further identify the putative channel or transporter responsible for the observed synergistic effects of Prob on BP treatment we applied additional blockers for pyrophosphate channels, organic anion transporters and blockers for multidrug resistance associated protein 1. MDA-MB231 breast cancer cells were stimulated with $50 \mu \mathrm{M}$ ZA, RIS, IBN, or ALN, respectively and co-treated with $50 \mu \mathrm{M}$ carbenoxolone (CBX), a blocker of PANX1, $100 \mu \mathrm{M}$ novobiocin, a blocker for solute carrier family 22 member 6,8 and 11 (SLC22A6, SLC22A8, SLC22A11) and $50 \mu \mathrm{M}$ ibrutinib, an inhibitor for multidrug resistance associated protein 1 (ABCC1) for $72 \mathrm{~h}$. Determination of cell viability showed a synergistic effect on the inhibition of cell viability of $\mathrm{CBX}$ and ZA compared to ZA alone in MDAMB-231 cells, all other combinations had no significant effects (Figure 6A). No synergistic effect of CBX in terms of caspase $3 / 7$ activity induction compared to bisphosphonate stimulations alone could be observed (Figure 6B). Novobiocin plus BP synergistically and highly significantly reduced cell viability of MDA-MB-231 cells with novobiocin/ZA being the most potent combination compared to BP stimulations alone (Figure 6A). Caspase 3/7 activity was synergistically and significantly induced by the combination novobiocin/RIS and novobiocin/IBN while novobiocin/ZA decreased caspase 3/7 activity compared to BP treatment alone (Figure 6B). Ibrutinib plus ZA significantly induced cell viability compared to BP treatment alone (Figure 6A) while caspase $3 / 7$ activity was significantly decreased by the combination ibrutinib/ZA and ibrutinib/ALN compared to BP alone (Figure 6B). Carbenoxolone, novobiocin and ibrutinib alone did not influence cell viability and caspase $3 / 7$ activity (data not shown). Significances were calculated with the MannWhitney $U$ test by comparison of the BP stimulated samples to the BP/CBX co-treated values $\left({ }^{*} \mathrm{p}<0.05\right.$; *** $\mathrm{p}<0.005)$. 

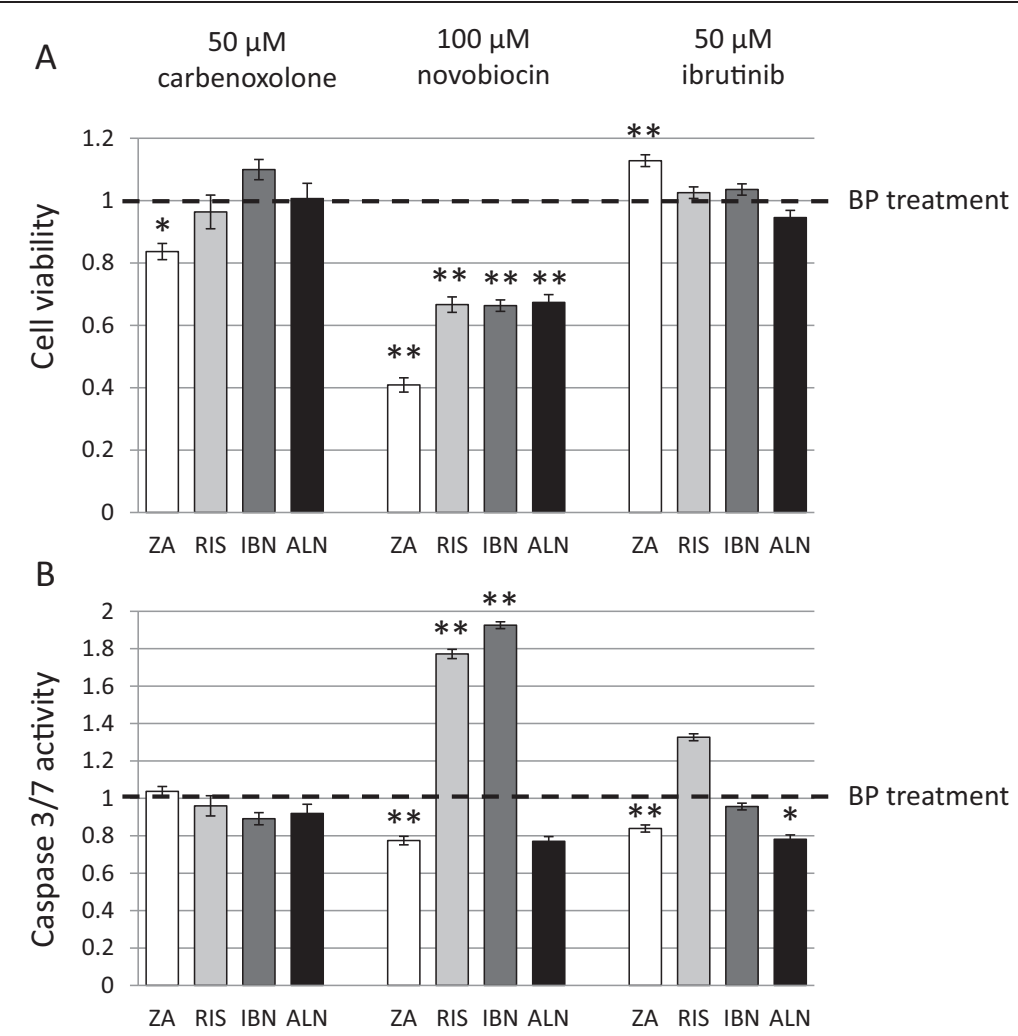

Figure 6 Cell viability and caspase 3/7 activity in MDA-MB-231 cells co-treated with carbenoxolone, novobiocin, ibrutinib and bisphosphonates. Cell viability (A) and caspase 3/7 activity (B) was determined after treatment with ZA (zoledronic acid), RIS (risedronate), IBN (ibandronate), ALN (alendronate) in combination with carbenoxolone, novobiocin and ibrutinib. All data are expressed as means of three different measure points of three independent experiments \pm SEM and were normalized to BP treatment alone. Significances were calculated with the Mann Whitney $U$ test $\left({ }^{*} p<0.05 ;{ }^{* *} p<0.005\right)$.

\section{Discussion}

Apart from osteoclasts, BP may have clinically relevant effects on benign and malignant cells. We found variable efficacies of different BP on cell viability and caspase 3/7 activity of the breast cancer cell lines MDA-MB-231, T47D and MCF-7. The most potent BP in MDA-MB-231 cells with respect to caspase $3 / 7$ activity induction was $\mathrm{ZA}$, while other BP were markedly less effective in the descending order IBN $>$ ALN $>$ RIS when applied in equimolar concentrations. In the apoptosis insensitive cell lines the picture was different with ZA showing high efficacy on the reduction of cell viability in T47D cells followed by ALN, IBN and RIS in contrast to MCF-7 cells where ZA and ALN depicted comparable effects followed by the weaker compounds RIS and IBN. The observed differences cannot be explained by the rank order of BP in their potency to inhibit the target enzyme farnesyl pyrophosphate synthase (FPPS) with ZA and RIS depicting the highest potency followed by the much weaker inhibitors IBN and ALN [4]. Differences in cellular BP uptake and retention might be responsible for these observations. Nothing is known if all BP are incorporated with the same efficacy, also the mechanism by which tumor cells take up
$\mathrm{BP}$ is under discussion. The process of pinocytosis might be relevant but the transport through a channel protein cannot be excluded. At pH 7.4 the amino-BP differ in their zeta potential as the R2 groups of ZA, ALN and IBN are positively charged in contrast to RIS, where the group is negatively charged [4]. Analyses with nanoparticles revealed that positively charged particles are more likely engulfed by pinocytosis than negatively charged particles [36] but also a channel protein or a transporter might distinguish between the different groups in favor of the positively charged BP. Both processes would lead to reduced RIS uptake possibly explaining the weak effects of this compound in tumor cells.

The determination of IPP accumulation and ApppI formation revealed differences between the analyzed breast cancer cell lines and the various BP. In T47D cells we detected high levels of IPP/ApppI and in MCF-7 cells high to moderate levels of IPP and low levels of ApppI as reported previously [19]. In MDA-MB-231 cells IPP and ApppI were only measurable in single samples. ZA was the most potent BP in inducing IPP/ApppI followed by RIS and ALN and IBN being the weakest compound. Our data are not in line with observations in J774 macrophages 
where ApppI was highest after ZA treatment followed by RIS, IBN and ALN [5], which is similar to their known order of affinity to FPPS and we again speculate that cells incapable of phagocytosis reflect mechanisms for BP uptake, which distinguish between differently charged BP.

Tumor cells are capable of releasing IPP to the extracellular space, which can bind to an unknown antigen-presenting molecule to be recognized by the T-cell receptor of $\gamma \delta$ T-cells $[20,21]$. The mechanisms by which IPP is secreted are unknown and we assumed that the pyrophosphate channels PANX1 and/or ANKH or organic anion transporters as ABCC1 and/or members of the organic anion transporter family SLC22A might mediate this release. All analyzed breast cancer cells depicted similar expression levels of PANX1 and ABCC1 whereas a considerable variability of ANKH and SLC22A11 expression was observed. At first our lead candidate was ANKH but by establishing ANKH transgenic T47D cells we were able to exclude its relevance. We further hypothesized that blocking the above mentioned channels and transporters and subsequently inhibiting the release of BP-induced pyrophosphates enhances IPP/ApppI accumulation, leading to an increase in the $\mathrm{BP}$ effect on tumor cell viability. Co-stimulation with the PANX1 inhibitor CBX or the ABCC1 inhibitor ibrutinib together with BP did not result in an appreciable synergistic effect in contrast to a co-stimulation with $\mathrm{BP}$ and the organic anion transporter and pyrophosphate channel blocking agent probenecid (Prob) or the SLC22A blocker novobiocin. Both probenecid and novobiocin revealed remarkable additive effects on BP-mediated cell viability reduction and caspase $3 / 7$ activity induction in certain conditions. Therefore we hypothesize that solute carrier family 22 (organic anion transporter) members might be the main candidates to release IPP into the extracellular space. By blocking SLC22A members the described effects of BPs on tumor cells can be intensified.

Furthermore we tried to find out if the additive effect of Prob and BP on tumor cell viability is consistent with an increase in intracellular IPP and ApppI. The most remarkable induction of pyrophosphate accumulation was observed in samples showing low BP-induced IPP/ApppI levels like in IBN and ALN treated T47D cells. T47D cells are generally able to accumulate IPP/ApppI in high amounts as it was reported before [19]. MCF-7 lack the expression of SLC22A11 while T47D show only low expression of ANKH in contrast to MDA-MB-231 cells. MDA cells produce comparably high levels of the three channels/transporters ANKH, PANX1 and SLC22A11 and this is a possible explanation why the intracellular levels of IPP and consecutively ApppI can not be measured.

Equimolar concentrations of IPP and AMP are necessary for the formation of ApppI, catalyzed by aminoacyltRNA synthase enzymes. The concentration of AMP is dependent on the cellular energy metabolism. ApppI formation sequestrates AMP, which is then not available for mitochondrial ATP regeneration and ApppI itself blocks the adenine nucleotide translocases, which catalyzes the exchange of cytoplasmic ADP with mitochondrial ATP across the mitochondrial inner membrane. The molecular consequences of ATP deficiency are a negative energy balance and either reduction of proliferation or apoptosis induction, the latter being dependent on the individual susceptibility of cells to induce the apoptosis program. This condition is perfectly reflected by the ATP-based proliferation measurement, which we used for the determination of cell viability. The intracellular pool of nucleotides for energy metabolism and nucleic acid synthesis appears to be different in the used cell lines. In apoptosis sensitive cells this leads to caspase 3/ 7 activity induction while in resistant cells proliferation is inhibited.

Our data may also shed light on the mechanisms of regulation of intracellular versus extracellular concentrations of phosphate compounds through channel-mediated release in general. As we showed earlier, ZA enhanced mineralization of osteogenic precursors in vitro [32]. Inorganic pyrophosphates are inhibitors of mineralization and upon inhibition of the delivery of these pyrophosphates to the cell surface through both stimulation of intracellular decoy mechanisms and inhibition of channel delivery mineralization should be increased around cells that are able to perform coordinated mineralization processes. Further research will have to unravel this putatively pathology-relevant role of channel activity.

\section{Conclusion}

In summary, we report an antitumor activity of all aminoBP, which can be enhanced through inhibition of a putative channel for IPP and by the consecutive rise of intracellular substrates and products of ATP-derived adducts. Probenecid, approved as an uricosuric compound, which inhibits the reabsorption of uric acid, and the antibiotic novobiocin, are accredited compounds. If the effect of enhancing anti-tumor effects of BP using concomitant probenecid or novobiocin treatment can be translated into preclinical and clinical settings without deleterious off-target effects remains to be proven.

\section{Methods}

\section{Cell culture}

All media were obtained from Life Technologies $\mathrm{GmbH}$ (Darmstadt, Germany), fetal calf serum (FCS) was obtained from Biochrom AG (Berlin, Germany). MCF-7, MDA-MB231 and T47D cells were cultivated as described previously [15]. As all experiments were performed with cell lines an ethical approval was not required. 
Establishment of stable ANKH overexpressing T47D cells $2.5 \times 10^{5}$ T47D cells per well were seeded on 6well plates and transfected with $2.5 \mu \mathrm{g}$ pCMV-ANKH (Sino Biological Inc., Beijing, PR China) or the empty pCMV vector, both linearized with SspI (New England Biolabs, Frankfurt, Germany), by using LipofectAMINE 2000 (Life Technologies GmbH, Darmstadt, Germany) according to the manufacturer's instructions. As selection antibiotics $100 \mu \mathrm{g} / \mathrm{ml}$ hygromycin (Life Technologies $\mathrm{GmbH}$ ) was added with every medium change.

\section{Determination of cell viability and caspase $3 / 7$ activity}

For determination of effects of bisphosphonates on cell viability and caspase 3/7 activity MDA-MB-231, T47D and MCF-7 as well as T47D-pCMV-ANKH and T47D-pCMV control cells were seeded on 96-well plates with a density of 1000 cells/well and were stimulated with 5, 20, 50 and $100 \mu \mathrm{M}$ zoledronic acid (ZA), ibandronate (IBN), alendronate (ALN) and risedronate (RIS) (AXXORA GmbH, Lörrach, Germany) for $72 \mathrm{~h}$. To analyze effects of probenecid (Prob) co-treatment MCF-7, MDA-MB-231 and T47D cells were stimulated with $0.25 \mathrm{mM}$ Prob (Sigma Aldrich $\mathrm{GmbH}$ ) together with 20, 50 or $100 \mu \mathrm{M} \mathrm{ZA,} \mathrm{ALN,}$ RIS and IBN, respectively. Additional co-stimulatory experiments were performed by using $50 \mu \mathrm{M}$ carbenoxolone (CBX, Sigma Aldrich GmbH), $5 \mu \mathrm{M}$ ibrutinib, $100 \mu \mathrm{M}$ novobiocin (both Selleckchem, Houston, USA) together with $50 \mu \mathrm{M}$ of each bisphosphonate. Cell viability and caspase $3 / 7$ activity were determined after $72 \mathrm{~h}$ with the CellTiter-Glo Luminescent Cell Viability Assay and the Caspase-Glo 3/7 Assay (both Promega GmbH, Mannheim, Germany) according to the manufacturer's instructions as described previously [15]. Cytotoxicity was determined in MCF-7 and MDA-MB-231 cells after ZA treatment by using the CytoTox-Fluor ${ }^{\text {ru }}$ Cytotoxicity Assay (Promega $\mathrm{GmbH}$ ) according to the manufacturer's instructions. Significances were calculated with the Mann-Whitney U Test by comparison of the untreated control to the stimulated values and by comparison of BP treated cells to $\mathrm{BP} /$ Prob or BP/CBX co-stimulated cells.

\section{RT-PCR}

Total RNA was isolated from MCF-7, T47D and MDAMB-231 cells by using the NucleoSpin RNA II kit (Macherey-Nagel, Düren, Germany) according to the manufacturer's instructions. Two micrograms of total RNA were reverse-transcribed with MMLV reverse transcriptase (Promega GmbH) in a volume of $25 \mu$ l. For amplification of ABCC1, ANKH, PANX1, SLC22A6, SLC22A8, SLC22A11 and the housekeeping gene EF1 $\alpha$ $1 \mu \mathrm{l}$ of cDNA was used as a template in a volume of $50 \mu \mathrm{l}$. Taq DNA polymerase was obtained from Promega $\mathrm{GmbH}$ and primers were obtained from biomers $\mathrm{GmbH}$, Ulm, Germany with the following sequences in $5^{\prime}-3^{\prime}$ direction: $\mathrm{ABCC}_{\text {for }}$ GGATTTTTGCTGTGGATCGT; AB $\mathrm{CC}_{\text {rev }}$ ACCAGCCAGAAAGTGAGCAT; ANKH $\mathrm{H}_{\text {for }}$ AAA GCCGTCCTGTGTATGGT; ANKH ${ }_{\text {rev }}$ CAGGGATGATG TCGTGAATG; PANX1 $1_{\text {for }}$ AGAGCGAGTCTGGAAACC; PANX1 $1_{\text {rev }}$ CAAGTCTGAGCAAATATGAGG; SLC22A6 $6_{\text {for }}$ GTCTGCAGAAGGAGCTGACC; SLC22A6 ${ }_{\text {rev }}$ GTCCAC AGCACCAAAGATCA; SLC22A8 for $_{\text {fo }}$ CTAGCACCGTC ATCTTGAA; SLC22A $8_{\text {rev }}$ TGGTGTCCACCAGGATGA TA; SLC22A11 for $_{\text {CTGCCCTCTTGCTCAGTTTC; SLC }}$ $22 \mathrm{~A} 11_{\text {rev }}$ CACTGGCGTTGGAAAGAGTT; $\mathrm{EF} 1 \alpha_{\text {for }}$ AGG TGATTATCCTGAACCATCC; EF1 $\alpha_{\text {rev }}$ AAAGGTGGAT AGTCTGAGAAGC. PCR conditions were as follows: $30 \mathrm{~s}$, $94^{\circ} \mathrm{C}$; $30 \mathrm{~s}$, annealing temperature $\left(54^{\circ} \mathrm{C} \mathrm{EF} 1 \alpha, 55^{\circ} \mathrm{C} \mathrm{ANKH}\right.$, $57^{\circ} \mathrm{C}$ PANX1, $60^{\circ} \mathrm{C} \mathrm{ABCC1,} \mathrm{SLC22A6} \mathrm{and} \mathrm{SLC22A11,}$ $62^{\circ} \mathrm{C}$ SLC22A8), $30 \mathrm{~s}, 72^{\circ} \mathrm{C}$; 35 cycles. PCR bands were analyzed by agarose gel electrophoresis.

\section{Quantitative PCR}

MDA-MB-231, T47D and MCF-7 cells were treated for $72 \mathrm{~h}$ with 20 or $50 \mu \mathrm{M}$ ZA, RIS, IBA, ALN as indicated and co-treated with $0.25 \mathrm{mM}$ probenecid. Quantitative PCR (qPCR) was performed in $20 \mu \mathrm{l}$ by using $1 \mu \mathrm{l}$ of the cDNA, which was previously diluted 1:5 and $10 \mu \mathrm{l}$ of KAPA SYBR FAST qPCR Universal Mix (Peqlab Biotechnologie GmbH, Erlangen, Germany) and $2.5 \mu \mathrm{l}$ of primer pairs for human KLF2 or GAPDH as housekeeping gene (Quantitect Hs KLF2_1 and Hs_GAPDH_1_SG, Qiagen GmbH, Hilden, Germany), dissolved according to the manufacturer's instructions. The primers for 36B4, which was used as housekeeping gene, and the primers for $\mathrm{ABCC} 1, \mathrm{ANKH}$, and PANX1 (see above) were obtained from biomers.net $\mathrm{GmbH}$, Ulm, Germany and were used in a concentration of 1 pmol each per reaction with the following sequences in 5'-3' direction: 36B4_qFor: TGCATCAGTACCCC ATTCTATCAT; 36B4_qRev: AGGCAGATGGATCAG CCAAGA [37]. QPCR conditions were as follows: $95^{\circ} \mathrm{C}$, 3 min; 40 cycles: $95^{\circ} \mathrm{C}, 15 \mathrm{~s} ; 60^{\circ} \mathrm{C}, 15 \mathrm{~s} ; 72^{\circ} \mathrm{C}, 20 \mathrm{~s}$; followed by melting curve analysis for specificity of qPCR products. QPCR was performed with the Opticon DNA Engine (MJ Research, Waltham, USA). Data were obtained from three independent experiments and qPCRs were performed three times. Results were calculated with the Relative Expression Software Tool (REST 2009 V2.0.13) obtained from Qiagen $\mathrm{GmbH}$ [38].

\section{Immunocytochemistry for ANKH and PANX1}

Breast cancer cells were seeded on coverslips in 6well plates, grown over night, washed thrice with PBS, fixed for 5 min with ice-cold methanol, dried and stored at $-80^{\circ} \mathrm{C}$ until staining. Before staining cells were washed with PBS, permeabilized with $\mathrm{PBS} / 0.05 \%$ Tween-20, washed again with PBS, and blocked with 3\% BSA in PBS. Cells were incubated with the primary antibodies for ANKH (1:300 (sc-67242) and PANX1 (1:500 sc-49695), respectively 
(both Santa Cruz Biotechnology, Inc., Heidelberg, Germany) for $16 \mathrm{~h}$ at $4^{\circ} \mathrm{C}$ and a phycoerythrin-labeled secondary antibody (NorthernLights anti-mouse IgG-NL557, RnD Systems, NL007, 1:400) for $2 \mathrm{~h}$ at RT. The coverslips were transferred on slides with a drop of Vectashield with DAPI (LINARIS GmbH, Wertheim, Germany) and analyzed under a fluorescence microscope (Axioskop2, filters 1 and 20, Carl Zeiss MicroImaging GmbH, Jena, Germany).

\section{Determination of IPP and Apppl in cell samples}

IPP and ApppI were determined as described previously [5]. Briefly, $1 \times 10^{6}$ MCF-7, MDA-MB-231 and T47D cells/ well were seeded on 6well plates and incubated overnight. MCF-7 cells were stimulated with $20 \mu \mathrm{M} Z A$ and $50 \mu \mathrm{M}$ of all other BP (RIS, IBN, ALN), MDA-MB-231 and T47D cells were treated with $50 \mu \mathrm{M}$ BP (ZA, RIS, IBN, ALN), $0.25 \mathrm{mM}$ Prob or the combination of each BP and Prob for $24 \mathrm{~h}$, washed with ice-cold PBS and harvested. IPP/ ApppI was extracted with ice-cold acetonitrile $(300 \mu \mathrm{l})$ and water $(200 \mu \mathrm{l})$ containing $0.25 \mathrm{mM} \mathrm{NaF}$ and $\mathrm{Na}_{3} \mathrm{VO}_{4}$ as phosphatase inhibitors. IPP and ApppI were quantified with HPLC-ESI-MS, protein contents were determined by the BCA method (Perbio Science Deutschland, Bonn, Germany). Values were obtained from three independent experiments.

\section{Additional files}

Additional file 1: Figure S1. Immunocytochemical staining of ANKH and PANX1, nuclei are stained with DAPI. Representative images are shown, the bar represents $100 \mu \mathrm{m}$.

Additional file 2: Figure S2. Overexpression of ANKH in T47D cells. A) Amplification of ANKH in pCMV-ANKH and pCMV stable cell lines. EF1a was used as a housekeeping gene. B) Immunocytochemical staining of ANKH in pCMV-ANKH and pCMV stable T47D cells. Nuclei are stained with DAPI. Representative images are shown, the bar represents $100 \mu \mathrm{m}$. C) Cell viability and caspase $3 / 7$ activity in pCMV-ANKH and pCMV stable T47D cells co-treated with probenecid and ZA. All data are expressed as means of six different measure points of three independent experiments as percent of controls \pm SEM. BP: bisphosphonate, black line; Prob: probenecid, dotted line probenecid co-treatment.

\section{Abbreviations}

ABCC1: ATP-Binding Cassette, Sub-Family C (CFTR/MRP), Member 1; ALN: Alendronate; ANKH: progressive ankylosis protein homolog; Apppl: triphosphoric acid 1-adenosin-5-yl ester 3-(3-methylbut-3-enyl) ester; BP: Bisphosphonates; CBX: Carbenoxolone; DAPI: 4',6-diamidino-2phenylindole; EMT: Epithelial mesenchymal transition; FCS: Fetal calf serum; FPPS: Farnesyl pyrophosphate synthase; GAPDH: Glyceraldehyde-3phosphate dehydrogenase; hMSC: human mesenchymal stem cells; IBN: Ibandronate; IPP: Isopentenyl pyrophosphate; PANX: Pannexin; PBS: Phosphate buffered saline; Prob: Probenecid; qPCR: quantitative polymerase chain reaction; RIS: Risedronate; SLC: Solute carrier family; ZA: Zoledronic acid.

\section{Competing interests}

All authors have no conflicts interests except: Franz Jakob receives honoraria for lectures and consulting from Novartis, Procter \& Gamble, Servier, Lilly, MSD, and Roche. Lorenz Hofbauer receives honoraria for lectures and consulting from Amgen, Novartis, Servier, and Merck. Tilman Rachner has received honoraria for consulting and unrestricted research grants from Novartis and MSD.

\section{Authors' contributions}

RE participated in the design of the study and wrote the manuscript, JMW, SG, and BM carried out the proliferation and apoptosis assays, SZ carried out the GPCR analyses, JM, SA and SCS carried out the IPP/Apppl measurements. $\mathrm{LH}$ and TR drafted the manuscript, FJ conceived the study, participated in the design of the study and drafted the manuscript. All authors read and approved the final manuscript.

\section{Acknowledgement}

This publication was funded by the German Research Foundation (DFG) and the University of Würzburg in the funding programme Open Access Publishing.

\section{Author details}

${ }^{1}$ Orthopedic Center for Musculoskeletal Research, University of Würzburg, Brettreichstrasse 11, 97074 Würzburg, Germany. ${ }^{2}$ Division of Endocrinology, Diabetes and Bone Metabolism, Technical University of Dresden,

Fetscherstrasse 74, 01307 Dresden, Germany. ${ }^{3}$ School of Pharmacy, University of Eastern Finland, Yliopistonranta 1C, POB 1627, 70211 Kuopio, Finland.

Received: 29 January 2014 Accepted: 27 November 2014

Published: 11 December 2014

\section{References}

1. Hofbauer LC, Rachner T, Singh SK: Fatal attraction: why breast cancer cells home to bone. Breast Cancer Res 2008, 10:101.

2. Kakonen SM, Mundy GR: Mechanisms of osteolytic bone metastases in breast carcinoma. Cancer 2003, 97:834-839.

3. Russell RG, Xia Z, Dunford JE, Oppermann U, Kwaasi A, Hulley PA, Kavanagh KL, Triffitt JT, Lundy MW, Phipps RJ, Barnett BL, Coxon FP, Rogers MJ, Watts NB, Ebetino FH: Bisphosphonates: an update on mechanisms of action and how these relate to clinical efficacy. Ann N Y Acad Sci 2007, 1117:209-257.

4. Russell RG, Watts NB, Ebetino FH, Rogers MJ: Mechanisms of action of bisphosphonates: similarities and differences and their potential influence on clinical efficacy. Osteoporos Int 2008, 19:733-759.

5. Monkkonen $\mathrm{H}$, Auriola S, Lehenkari P, Kellinsalmi M, Hassinen IE, Vepsalainen J, Monkkonen J: A new endogenous ATP analog (Apppl) inhibits the mitochondrial adenine nucleotide translocase (ANT) and is responsible for the apoptosis induced by nitrogen-containing bisphosphonates. $\mathrm{Br} J$ Pharmacol 2006, 147:437-445.

6. Costa L, Major PP: Effect of bisphosphonates on pain and quality of life in patients with bone metastases. Nat Clin Pract Oncol 2009, 6:163-174.

7. Holen I, Coleman RE: Bisphosphonates as treatment of bone metastases. Curr Pharm Des 2010, 16:1262-1271.

8. Clines GA, Guise TA: Molecular mechanisms and treatment of bone metastasis. Expert Rev Mol Med 2008, 10:e7.

9. Diel IJ, Solomayer E-F, Costa SD, Gollan C, Goerner R, Wallwiener D, Kaufmann M, Bastert G: Reduction in New Metastases in Breast Cancer with Adjuvant Clodronate Treatment. N Engl J Med 1998, 339:357-363.

10. Gnant M, Mlineritsch B, Schippinger W, Luschin-Ebengreuth G, Postlberger S, Menzel C, Jakesz R, Seifert M, Hubalek M, Bjelic-Radisic V, Samonigg H, Tausch C, Eidtmann H, Steger G, Kwasny W, Dubsky P, Fridrik M, Fitzal F, Stierer M, Rücklinger E, Greil R, ABCSG-12 Trial Investigators, Marth C: Endocrine therapy plus zoledronic acid in premenopausal breast cancer. N Engl J Med 2009, 360:679-691.

11. Diel IJ, Jaschke A, Solomayer EF, Gollan C, Bastert G, Sohn C, Schuetz F: Adjuvant oral clodronate improves the overall survival of primary breast cancer patients with micrometastases to the bone marrow: a long-term follow-up. Ann Oncol 2008, 19:2007-2011.

12. Coleman RE, Winter MC, Cameron D, Bell R, Dodwell D, Keane MM, Gil M, Ritchie D, Passos-Coelho JL, Wheatley D, Burkinshaw R, Marshall SJ, Thorpe H, AZURE (BIG01/04) Investigators: The effects of adding zoledronic acid to neoadjuvant chemotherapy on tumour response: exploratory evidence for direct anti-tumour activity in breast cancer. $\mathrm{Br} J$ Cancer 2010, 102:1099-1105.

13. Coleman R, de Boer R, Eidtmann H, Llombart A, Davidson N, Neven P, von Minckwitz G, Sleeboom HP, Forbes J, Barrios C, Frassoldati A, Campbell I, Paija O, Martin N, Modi A, Bundred N: Zoledronic acid (zoledronate) for 
postmenopausal women with early breast cancer receiving adjuvant letrozole (ZO-FAST study): final 60-month results. Ann Oncol 2013, 24:398-405.

14. Hofbauer LC, Rachner T, Coleman R, Jakob F: Endocrine aspects of bone matastases. Lancet Diabetes Endocrinol 2014, 2:500-512.

15. Ebert R, Zeck S, Meissner-Weigl J, Klotz B, Rachner TD, Benad P, Klein-Hitpass L, Rudert M, Hofbauer LC, Jakob F: Kruppel-like factors KLF2 and 6 and Ki-67 are direct targets of zoledronic acid in MCF-7 cells. Bone 2012, 50:723-732

16. Rachner TD, Singh SK, Schoppet M, Benad P, Bornhauser M, Ellenrieder V, Ebert R, Jakob F, Hofbauer LC: Zoledronic acid induces apoptosis and changes the TRAIL/OPG ratio in breast cancer cells. Cancer Lett 2010, 287:109-116.

17. Shmeeda H, Amitay Y, Gorin J, Tzemach D, Mak L, Ogorka J, Kumar S, Zhang JA, Gabizon A: Delivery of zoledronic acid encapsulated in folate-targeted liposome results in potent in vitro cytotoxic activity on tumor cells. J Control Release 2010, 146:76-83.

18. Roelofs AJ, Thompson K, Gordon S, Rogers MJ: Molecular mechanisms of action of bisphosphonates: current status. Clin Cancer Res 2006, 12:6222s-6230s.

19. Benzaid I, Monkkonen H, Stresing V, Bonnelye E, Green J, Monkkonen J, Touraine $J L$, Clezardin P: High Phosphoantigen Levels in BisphosphonateTreated Human Breast Tumors Promote V\{gamma\}9 V\{delta\}2 T-Cell Chemotaxis and Cytotoxicity In Vivo. Cancer Res 2011, 71:4562-4572.

20. Morita CT, Jin C, Sarikonda G, Wang H: Nonpeptide antigens, presentation mechanisms, and immunological memory of human Vgamma2Vdelta2 $\mathrm{T}$ cells: discriminating friend from foe through the recognition of prenyl pyrophosphate antigens. Immunol Rev 2007, 215:59-76.

21. Clezardin P: Bisphosphonates' antitumor activity: an unravelled side of a multifaceted drug class. Bone 2011, 48:71-79.

22. Garre JM, Retamal MA, Cassina P, Barbeito L, Bukauskas FF, Saez JC, Bennett MV, Abudara V: FGF-1 induces ATP release from spinal astrocytes in culture and opens pannexin and connexin hemichannels. Proc Natl Acad Sci U S A 2010, 107:22659-22664.

23. Barbe MT, Monyer $H$, Bruzzone R: Cell-cell communication beyond connexins: the pannexin channels. Physiology (Bethesda) 2006, 21:103-114.

24. Silverman W, Locovei S, Dahl G: Probenecid, a gout remedy, inhibits pannexin 1 channels. Am J Physiol Cell Physiol 2008, 295:C761-C767.

25. Harmey D, Hessle L, Narisawa S, Johnson KA, Terkeltaub R, Millan JL: Concerted regulation of inorganic pyrophosphate and osteopontin by akp2, enpp1, and ank: an integrated model of the pathogenesis of mineralization disorders. Am J Pathol 2004, 164:1199-1209.

26. Zhou F, You G: Molecular insights into the structure-function relationship of organic anion transporters OATs. Pharm Res 2007, 24:28-36.

27. Cole SP: Targeting multidrug resistance protein 1 (MRP1, ABCC1): past, present, and future. Annu Rev Pharmacol Toxicol 2014, 54:95-117.

28. Prosdocimo DA, Douglas DC, Romani AM, O'Neill WC, Dubyak GR: Autocrine ATP release coupled to extracellular pyrophosphate accumulation in vascular smooth muscle cells. Am J Physiol Cell Physiol 2009, 296:C828-C839.

29. Ransford GA, Fregien N, Qiu F, Dahl G, Conner GE, Salathe M: Pannexin 1 contributes to ATP release in airway epithelia. Am J Respir Cell Mol Biol 2009, 41:525-534.

30. Zhang H, Patel A, Ma SL, Li XJ, Zhang YK, Yang PQ, Kathawala RJ, Wang YJ, Anreddy N, Fu LW, Chen ZS: In vitro, in vivo and ex-vivo characterization of ibrutinib: A potent inhibitor of MRP1 efflux function. Br J Pharmacol 2014, 171:5845-5857.

31. Duan P, You G: Novobiocin is a potent inhibitor for human organic anion transporters. Drug Metab Dispos 2009, 37:1203-1210.

32. Ebert R, Zeck S, Krug R, Meissner-Weigl J, Schneider D, Seefried L, Eulert J, Jakob F: Pulse treatment with zoledronic acid causes sustained commitment of bone marrow derived mesenchymal stem cells for osteogenic differentiation. Bone 2009, 44:858-864.

33. Duque G, Rivas D: Alendronate has an anabolic effect on bone through the differentiation of mesenchymal stem cells. J Bone Miner Res 2007, 22:1603-1611

34. Idris Al, Rojas J, Greig IR, Van't Hof RJ, Ralston SH: Aminobisphosphonates cause osteoblast apoptosis and inhibit bone nodule formation in vitro. Calcif Tissue Int 2008, 82:191-201.

35. Neville-Webbe HL, Coleman RE, Holen I: Combined effects of the bisphosphonate, zoledronic acid and the aromatase inhibitor letrozole on breast cancer cells in vitro: evidence of synergistic interaction. $\mathrm{Br} J$ Cancer 2010, 102:1010-1017.

36. Sahay G, Alakhova DY, Kabanov AV: Endocytosis of nanomedicines. J Control Release 2010, 145:182-195.

37. Boukhechba F, Balaguer T, Michiels JF, Ackermann K, Quincey D, Bouler JM, Pyerin W, Carle GF, Rochet N: Human primary osteocyte differentiation in a 3D culture system. J Bone Miner Res 2009, 24:1927-1935.

38. Pfaffl MW, Horgan GW, Dempfle L: Relative expression software tool (REST) for group-wise comparison and statistical analysis of relative expression results in real-time PCR. Nucleic Acids Res 2002, 30:e36.

doi:10.1186/1476-4598-13-265

Cite this article as: Ebert et al.: Probenecid as a sensitizer of bisphosphonate-mediated effects in breast cancer cells. Molecular Cancer 2014 13:265.

\section{Submit your next manuscript to BioMed Central and take full advantage of:}

- Convenient online submission

- Thorough peer review

- No space constraints or color figure charges

- Immediate publication on acceptance

- Inclusion in PubMed, CAS, Scopus and Google Scholar

- Research which is freely available for redistribution 